\title{
Ensino de literatura e leitura \\ como escritura na formação de professores: contribuiçoees do interacionismo socio-discursivo
}

Teaching of literature and reading as writing in teacher education: contributions of socio-discursive interactionism

Lidia Stutz

UNICENTRO /PR

Claudio José de Almeida Mello

UNICENTRO /PR

DOI: https://doi.org/10.5902/2176148534783

\begin{abstract}
Resumo: Apesar dos avanços no ensino de língua e literatura desde a década de 1980, a literatura continua sendo utilizada em muitas escolas com propósitos distintos da experiência estética por parte do leitor. Com o objetivo de contribuir para a equalização dos propósitos e meios do ensino de literatura na formação de professores, este estudo apresenta um percurso sobre as concepções de leitor e leitura na tradição escolar e destaca a contribuição do Interacionismo Sociodiscursivo para a consideração da leitura como escritura na formação do leitor.
\end{abstract}

Palavras-chave: Educação literária. Formação do leitor. Leitura. Produção de textos.

Abstract: Despite advances in the teaching of language and literature since the 1980s, literature has been developed in many schools with different objectives than that of reader's aesthetic experience. In order to contribute to the equalization of the purposes and means of literature teaching in teacher's education, this article presents a pathway of the conceptions of reader and reading in the schooling tradition and highlights the contribution of the Sociodiscursive Interactionism for the consideration of reading as writing in the reader's education.

Key words: Literary education. Reader education. Reading. Production of texts. 
Lidia Stutz

Claudio José de Almeida Mello

\section{Introdução}

Este artigo apresenta um percurso sobre o papel do leitor como sujeito ativo no processo de leitura e escritura do texto literário. Se a concepção de leitura como decodificação - hegemônica no passado mas ainda presente em muitas realidades escolares - orientava um papel passivo ao leitor de textos em geral, nos textos literários esse papel se manifestava em uma postura de admiração, incentivada na escola em lições sobre como analisar ou como interpretar para admirar.

Mas a partir das teorias que reconhecem o papel responsivo do leitor, sob a ancoragem da concepção interacionista de linguagem e das teorias recepcionais, ocorrem modificações significativas nas concepções de leitura e na forma de ensinar a ler e a escrever, assim como na formação docente. Nos novos paradigmas, a compreensão de textos necessariamente se faz pela interação entre leitor e texto, considerando-se o contexto de produção e circulação do texto, os parâmetros organizacionais, enunciativos e de textualização, produzindo uma leitura que se desenvolve a contra-pelo e se afirma como reescritura, dessacralizando o texto.

O presente estudo relaciona esse referencial teórico à promoção da leitura e também da escrita literária com o objetivo de explicitar a produtividade de se utilizar elementos de transposição didática de gêneros textuais para a apreensão de saberes docentes na formação inicial de professores, como alternativa para a formação do leitor/escritor literário.

\section{Escolarização da leitura literária: a literatura em perigo}

Considerando a história da escolarização da leitura literária, observa-se que a literatura já foi utilizada para diversos propósitos, perfazendo uma tradição que remonta os primórdios daquilo que hoje chamamos de estudos literários. Embora Aristóteles (s/d) não tenha se proposto a criar regras para o funcionamento da literatura ou para o falar bem, a apropriação que se fez de seu pensamento a partir do poeta latino Horácio durante a Idade Média e sobretudo na Idade Moderna se deu com um interesse didático evidente, instituindo um verdadeiro paradigma de modelo para a escrita e a oratória.

De fato, a tradução ao latim da Arte retórica e arte poética em 1498 deu grande projeção aos estudos de Aristóteles na Europa, cuja exegese crítica embasou o desejo de conhecer, analisar racionalmente e sistematizar o fenômeno literário, como aconteceu no Classicismo francês do Século XVII. Em 1674, Boileau, o mais ilustre dos estudiosos neoclas- 
sicistas, chegou a elaborar em sua Arte poética uma espécie de guia do bem escrever, recomendando evitar excessos, já que, para ele, a "demasia é cheia de ignorância", daí porque "o humilde estilo que namora se há de ver nos Idílios elegantes" (AMORA, 1973, p. 78).

A boa escrita se conjugava, ainda, à postulação de um comportamento moral, retomando o binômio de Horácio, de que a literatura deveria ser dulce et utile. Nessa linha, grandes escritores franceses dessa época desenvolveram a função moral da literatura, como Moliére, pelo riso dos vícios das comédias, Racine, pelo ensino com conotações morais das tragédias, e La Fontaine, pela moral das fábulas (AMORA, 1973).

Assim, o caminho para se atingir o que então se idealizava como a perfeição literária casou bem com a preocupação retórica concebida como a arte de usar a linguagem mais clara, correta e elegante, capaz de convencer e influenciar por meio de modelos de escrever bem e mesmo falar bem. A força dessa tradição se espraiou pelo Ocidente, influenciando modelos de ensino e de comportamento social, e ressoa ainda nos dias correntes.

Já no início da escolarização do Brasil colonial, as práticas pedagógicas para o ensino da leitura concentravam-se em textos literários clássicos, escritos em latim, revelando uma postura "claramente reprodutivista, voltada para a perpetuação de uma ordem patriarcal, estamental e colonial. Assim, priorizaram [...] uma não-pedagogia, acionando no cotidiano o aparato repressivo para inculcar a obediência [à fé, ao rei e à lei]" (VILLALTA, 1997, p. 351). Desde então, uma das práticas associadas à idealização da perfeição literária e ao paradigma do modelo é a tradição da cópia como prática de ensino, recorrente ainda quando os autores deste artigo frequentavam os primeiros anos escolares, na década de 1970 .

O ensino da literatura nessa visão clássica está arraigado na prática da reprodução fiel de expressões do texto, na mera seleção lexical, na leitura organizada que coloca o professor como detentor da interpretação aceita. A leitura segue na esteira da neutralidade da linguagem, com a "seleção e hierarquização de obras e autores, apresentação cronológica dos textos e biografia dos escritores, articulação entre história, língua e fazer literário" (ABREU, 2003, p. 57).

Sabemos que toda atividade realizada em situações de ensino revela uma opção metodológica, alicerçada, no caso da língua e da literatura, em uma visão que o professor tem sobre a linguagem. Quando propõe um tal tipo de exercício, como "siga o modelo", "faça a cópia”, o 
Lidia Stutz

Claudio José de Almeida Mello professor, de um lado, transmite uma postura de admiração em relação ao texto fonte, o qual, por seu suposto alto nível de composição, mereceria ser imitado; e de outro lado, denota uma concepção de escrita como automática, cujo aprendizado baseia-se na reprodução de modelos preestabelecidos e valorizados por uma elite ilustrada.

Em ambos os casos, a atividade revela uma concepção de leitura como decodificação, um ato mecânico que propiciaria uma compreensão do sentido do texto, um modelo a ser reconstruído por meio de exercícios estruturais e técnicas de redação nas quais "a visão de reforço é acentuada, pois a aprendizagem é entendida como processada pela internalização inconsciente de hábitos (teoria comportamentalista/behaviorista)" (PERFEITO, 2007, p. 827).

A decodificação, ou modelo de leitura ascendente (bottom up) envolve processamentos de níveis mais baixos. Esses processamentos, para Gough (1972), resumem-se aos estímulos visuais, que permitem ao leitor visualizar e identificar as letras, fazer as devidas junções e pronunciar as palavras. Na sequência, a junção de palavras gera a construção das sentenças e, estas, por sua vez, estruturam-se e são reconhecidas conforme as classes gramaticais. A leitura centra-se no conteúdo e no texto como as principais fontes para a compreensão.

Esse viés, comum no ensino brasileiro dos anos 50 , pautava-se no ensino da norma culta por meio de textos literários para uma classe elitizada. A leitura preconizava a reprodução das representações dadas pelos autores, limitando-se o leitor a uma atitude passiva diante do texto, geralmente utilizado como pretexto para o ensino das formas gramaticais e de novos vocábulos (ROJO, 2004; SANTOS, 2012). Assim, o texto é concebido como um conjunto de sentenças com informações, cabendo ao leitor a mera extração de seus significados estáveis (KLEIMAN, 2008).

A concepção de leitura como decodificação se associa a uma concepção sistêmica de língua, baseada no sistema estrutural das relações linguísticas, tal como formulado por Saussure (1989), para quem "A abordagem descritiva do objeto, a noção de 'estrutura' forjada nas dualidades opositivas [...] forneceriam um método que permite analisar não somente a língua, mas todos os sistemas de signos da vida social" (WITZEL; MELLO, 2015).

Sob as lentes da filosofia da linguagem de Voloshinov (1975/2010, p. 74-75), essa concepção de linguagem volta-se para a tendência do "objetivismo abstrato", no qual a língua é constituída de elementos linguís- 
ticos que partem de um sistema fechado sem valor ideológico e os atos de fala são apenas deformações da forma normativa. Denominada como a concepção de linguagem da "expressão do pensamento como uma visão tradicional da língua" (GERALDI, 1990), a norma padrão como sistema estável e imutável delineia as representações sobre a língua e tem como fim a utilização correta da norma padrão. Na contra-mão dessa postura, alinhamos nosso olhar com Geraldi (1990) para compreender a linguagem no sentido amplo a partir do funcionamento do texto.

Ao tecer relações entre essa concepção de linguagem e o desenvolvimento do pensamento, Vigotski (1987/2008) identifica uma aproximação com a visão da reflexologia, que se ampara na associação e na formação de hábitos para considerar a aprendizagem e o desenvolvimento mental como uma acumulação gradual de reflexos condicionados. Nessa perspectiva, a

Ensino de literaturae leitura como escritura na formação de professores aprendizagem de uma língua ocorre por meio da repetição de unidades menores da língua, com foco em palavras isoladas e na forma. A partir dessas concepções de linguagem e leitura o ensino de língua é pautado no estudo de sua estrutura, na dissecação dos elementos da oração e nos exercícios de análise sintática como um fim em si (SOARES, 1998).

O ensino de literatura se vale da análise literária para identificação de mecanismos de composição da estrutura narrativa, como na taxonomia do espaço e do tempo ou no estudo das funções de personagens, na esteira da morfologia do conto de Vladmir Propp, ou da catalogação dos elementos do poema, como ritmo, rima e figuras de linguagem, seguindo o estudo intrínseco das particularidades da linguagem poética, sob a égide do Formalismo Russo (EIKHENBAUM, 1976).

Compreende-se por que a leitura literária e o ensino de literatura em ambiente escolar estejam permeados por essas práticas, uma vez que no sistema de ensino na maior parte das vezes se trata do mesmo professor de língua portuguesa e literatura, que possui as mesmas concepções de linguagem, texto e leitura. Em ambas as áreas, o trabalho pedagógico privilegia o estudo do texto em si, e não o uso social da língua ou a promoção da leitura literária e a experiência estética dos leitores. Tal fato levou Todorov (2009), justo ele, um estruturalista, a condenar o protagonismo que o modelo intrínseco de análise literária adquiriu no Ensino Secundário, reflexo do que se passa na formação inicial nos cursos de Letras.

$1 \quad$ Na obra de Geraldi 
Lidia Stutz

Claudio José de Almeida Mello
A abordagem que privilegia o texto, gerando uma atitude de admiração tanto pelo texto como pelo autor, espraiou-se pelo Ocidente. Analisando o caso da França, Houdart-Mérot (2013) reconhece que "o que predominou no ensino literário e em particular no ensino médio, no início do Século XX, foi o que poderíamos chamar de 'pedagogia da admiração'. Aprender a ler um texto literário no ensino médio, até os anos 1960, era aprender a admirar, tanto no plano estético quanto no moral".

A atitude de respeito aos textos verifica-se também em relação à história da literatura, como mostrou Todorov (2009) no caso francês, mas que ocorre também no Brasil, como identificou Oliveira (2007) em seis universidades paranaenses, nas quais a pesquisadora verificou uma hegemonia da transmissão da historiografia literária nos cursos de Letras, com a apresentação de estilos de época justapostos de forma

evolutiva e diacrônica. Tal modelo de ensino é reproduzido nos demais níveis de ensino, como constatou Piedras (2007) ao pesquisar quatro instituições de Ensino Médio de Porto Alegre. Segundo ela,

\footnotetext{
Os planos de conteúdos, tanto nas escolas particulares como nas públicas, mostram uma história da literatura com uma percepção historicista de evolução linear, baseada na continuidade. Não há fragmentação no alinhamento dos assuntos literários, que se organizam temporalmente, do mais distante ao mais próximo. (PIEDRAS, 2007, p. 84).
}

Verifica-se, portanto, uma espécie de círculo vicioso no ensino de literatura, em que o leitor figura como admirador ou reprodutor, um indivíduo que não ocupa a posição de agente responsivo perante aos textos literários: no Ensino Superior a transmissão da historiografia literária de orientação positivista e a análise literária intrínseca de viés formalista se reproduzem na Educação Básica, com a prática pedagógica da reprodução de modelos em uma tradição de admiração do autor e do texto.

\section{A morte do autor, novas concepções de leitura e o papel do leitor}

A manutenção dessas práticas tanto nos cursos de Letras como no Ensino Médio, como mostraram Oliveira (2007) e Piedras (2007), indica o quanto as transformações históricas na Educação são lentas, e como as práticas tardam em assimilar as inovações teóricas. 
Após “A morte do autor" preconizada por Barthes (2004), tão difundida nos cursos de Letras pelo país afora, a postura de admiração em relação ao autor e as práticas de ensino a ela associadas já deveriam estar superadas. Em seu ensaio, Barthes trata da dessacralização da entidade do autor, o qual perde sua função a partir do momento em que o texto é finalizado. Assim, "a escrita é a destruição de toda a voz, de toda

Ensino de literaturae leitura como escritura na formação de professores reunir no texto uma multiplicidade de inscrições, instaurando um diálogo com diversos outros textos. Como o texto é fértil de uma imensa diversidade cultural, sociológica, psicológica, social, histórica, ele não pode ser decifrado, por não ter um sentido único, estável. Com a morte do autor, avulta a figura do leitor, responsável pelas múltiplas significações do texto polissêmico (BARTHES, 2004).

Devido à ênfase no leitor no processo de recepção das obras literárias, Hans Robert Jauss (1994) chega a propor uma revisão das histórias da literatura, pelo fato de elas não terem considerado o seu papel na produção de sentidos dos textos. Para ele, a historicidade das obras é formada pelas múltiplas leituras realizadas nas diversas épocas pelos leitores reais. Portanto, também para Jauss não há porque buscar um sentido do texto, mas sim de considerar as possibilidades semânticas que os leitores construíram no ato da recepção.

$\mathrm{O}$ apagamento do papel do autor preconizado por Barthes se associa à subjetividade do leitor no ato da leitura enfatizada por Jauss. A base para tal formulação vem da hermenêutica de Gadamer (1997), com quem Jauss estudou: tal como a compreensão humana, que ocorre por meio de um diálogo entre o presente e o passado, entre o intérprete e a tradição, os sentidos da leitura são produzidos mediante uma fusão de horizontes de expectativas. De um lado, o horizonte contido na obra; de outro, o horizonte de expectativas do leitor, seus conhecimentos prévios, suas crenças, seus valores, sua ideologia, seus traumas. É por meio de sua subjetividade, portanto, que o leitor preenche os pontos de indeterminação da obra, realizando um todo compreensível. 
Lidia Stutz

Claudio José de Almeida Mello
Esse novo papel do leitor engendra um modelo de leitura de ordem descendente (top down), que envolve as representações e conhecimentos prévios do leitor e os orienta a partir de um olhar geral da configuração do texto. Trata-se de um movimento antagônico à leitura de decodificação, que partia das unidades menores do texto às maiores. No modelo top down, a leitura ocorre a partir das expectativas do leitor. Assim, o bom leitor é aquele capaz de inferir e participar do "jogo de adivinhações psicolinguísticas” (GOODMAN, 1967). Contrário ao modelo anterior, o leitor parte da "schemata" (CARREL; DEVINE; ESKEY, 1988/2000) como conhecimento específico da cultura e do conhecimento prévio da temática, da visão global para, a partir de elementos específicos como o título, fazer inferências com base em seu conhecimento prévio. Nessa formulação, a leitura eficiente é um processo seletivo que considera o uso parcial e mínimo do texto ou de pistas fornecidas pelo texto como elementos suficientes para produzir predições e inferências.

A junção dos modelos anteriores gera um terceiro, denominado de leitura interacionista, que mobiliza tanto o modelo ascendente quanto o descendente para construir o significado do texto. Esse modelo é bem aceito na literatura cognitivista de leitura e preconiza a combinação de dois níveis de processamento de pensamento, os inferiores, que correspondem aos procedimentos de decodificação, e os superiores, como as inferências e antecipações sobre o texto.

Da visão cognitivista para a sócio-interacionista, torna-se premente que o processamento do leitura, mesmo que no modelo interacionista ora apresentado, não desvela a dimensão interpsíquica, no sentido vigotskiano. Entram em cena as dimensões sociológicas e históricas advindas de condutas humanas que geram mobilizações de representações construídas pelo leitor/produtor do texto. Conforme já expomos na introdução, as dimensões advindas do contexto físico e sociossubjetivo (BRONCKART, 1999) são as responsáveis em prover compreensão sobre o contexto de ação da linguagem² .

Nas concepções sócio-interacionistas de leitura e a afirmação da subjetividade do leitor favorecem a construção de uma proposta pedagógica que reconheça o protagonismo do aluno como leitor-escritor e

2 Sob o viés sócio-histórico cultural, Cerutti-Rizatti, Daga e Dias (2014, p. 228, 229) utilizam as dimensões intersubjetiva e intrassubjetiva da leitura - sendo a primeira aliada aos elementos contextuais - "relação do 'eu' com o 'outro', mediada pela linguagem, em espaços social, histórica e culturalmente situados"; e a segunda aos elementos que abrangem o "universo lexical e gramatical da materialidade textual". 
orienta a formação de professores. O leitor passa da leitura como admiração à leitura scriptível, pois "a morte do autor, anunciada por Foucault e Roland Barthes, e a morte ou o questionamento da obra-prima vão provocar, na sequência, a morte oficial da admiração" (HOUDAR-MÉROT, 2013, p. 106).

O ensino da linguagem sob o viés eleito, explora sua totalidade na

Ensino de relação língua-literatura, não havendo como tratar dos aspectos estétiliteratura e cos sem tratar dos aspectos discursivos, visto que ambos se imbricam para gerar a significação. Assim, partimos da concepção de linguagem advinda da obra de Voloshinov (1980) que ultrapassa a ideia da língua em estado de dicionário para pensar a linguagem em uso, a ideia de grupo social, ideologia, tom e ambiente estão materializados no sujeito produtor do discurso artístico (BRAITH, 2010, p. 21).

leitura como escritura na formação de professores

Em vez dos textos unicamente legíveis, para usar um conceito difundido também por Barthes (1992) para caracterizar os textos fluidos ou fechados, por eles não permitirem o adentramento do leitor, a proposta é trabalhar com textos escrevíveis, que demandam uma leitura aplicada e incitam o leitor a se tornar um coprodutor dos sentidos. Assim, "o desafio do trabalho literário (da literatura como trabalho) é fazer do leitor não mais um consumidor, mas um produtor do texto" (BARTHES, 1992, p. 12). As propostas na perspectiva do interacionismo sociodiscursivo, seção apresentada na sequência, envolvem o ensino da compreensão e da produção sob o viés de gêneros textuais diversos, com o propósito maior de prover o letramento acadêmico do leitor que se torna também autor de textos, sejam eles literários ou não (SOUZA; MOULIN; COSTA, 2004).

Em situações de ensino de literatura, sobejam casos que podem servir de exemplo aos alunos de leituras-escrituras dessacralizadoras: a carnavalização desenvolvida por Rabelais em suas histórias, que procedem ao rebaixamento de textos oficiais ou sagrados; a antropofagia de Mário de Andrade e Oswald de Andrade, que instauram a tradição para subvertê-la, por meio da paródia, da intertextualidade provocativa; o questionamento da história oficial por José Saramago em seus romances históricos.

Baseado no conceito de textos scriptíveis, Violaine Houdar-Mérot propõe atividades pedagógicas para o ensino da literatura em que o leitor se apropria dos textos para alterá-los, discutir com eles, dessacralizá-los por meio da paródia, da alteração da focalização, da mudança do final da história, da substituição de palavras, da criação de personagens etc. Os 
Lidia Stutz

Claudio José de Almeida Mello exercícios de reescrita "poderiam, assim, permitir uma forma de leitura criativa e livre, complementar ao exercício de comentário que, por definição, é mais circunscrito e limitado pelas próprias restrições do texto e pelas comandas de interpretação" (HOUDAR-MÉROT, 2013, p. 114).

Outro estudo desenvolvido sobre a literatura e as relações com a escrita no meio escolar foi realizado por Schneuwly et al. (2017) em países francófonos, em diferentes níveis de ensino. Os resultados advindos da análise de 30 sequências de ensino em turmas diversas, com um gênero canônico (uma fábula de La Fontaine) e outro contemporâneo (um premiado conto suíço), mostraram que as atividades de escrita são recorrentes em todas as práticas, sejam elas por meio de propostas metatextuais, aliando as respostas subjetivas a formas mais canônicas, como produção de resumo e ensaio; sejam elas por meio de propostas de hipertextualização, com propósitos diferenciados, de acordo com o nível dos alunos. Os exercícios de reescrita em tela sempre partem da compreensão mobilizada e demandam posicionamento a partir do contexto e do olhar do leitor, para prover uma réplica ou uma atitude responsiva ativa, no dizer de Voloshinov (2010).

Não há dúvidas de que o papel ativo do leitor de textos literários melhora a sua capacidade de expressão linguística, tanto escrita quanto oral, contribuindo assim para a melhoria do seu letramento. Isso aponta para uma proposta pedagógica sem cisão entre ensino de língua e ensino de literatura, pois o trabalho com textos escrevíveis sempre envolve o contexto do aluno, seu posicionamento ideológico, a linguagem complexa e não transparente. As atividades dialógicas favorecem o surgimento em sala de aula de oportunidades de interação verbal, que geram ações de linguagem que se materializam em enunciados ou discursos como prática social, em momentos de negociação dos sentidos dos textos literários. Nessa concepção, a linguagem constitui o meio da interação, na qual "o sujeito que fala pratica ações que não conseguiria levar a cabo, a não ser falando, com ela o falante age sobre o ouvinte, constituindo compromissos e vínculos que não preexistiam à fala" (GERALDI, 1990, p. 41). Supera-se, assim, a leitura como simples decodificação, presa à literalidade dos textos e discursos e à simples interpretação, e passa-se a uma leitura desafiadora, que busca tecer relações entre os textos, discursos, ideologias e contexto social para, a partir desses aspectos, gerar réplicas e construir novos sentidos (ROJO, 2004). 


\section{Contribuições do Interacionismo Sociodiscursivo}

Buscando colocar em prática os referenciais teórico-metodológicos interacionistas expostos acima, destacamos a relevância do Interacionismo Sociodiscursivo na formação inicial de professores na área da formação do leitor-escritor literário, tendo em vista que esse referencial permite adentrar no processo de mediação formativa para prover uma base sólida para a aprendizagem dos professores em formação, compreendendo os "processos deliberados por meio dos quais os adultos (professores experientes) integram os 'recém-chegados' ao conjunto de pré-construídos disponíveis no seu ambiente sociocultural" (BRONCKART, 2006, p. 129, parênteses dos autores).

Sobretudo durante a formação profissional no estágio supervisionado, o desenvolvimento de uma práxis marcada pela alternância dos Ensino de literaturae leitura como escritura na formação de professores estudos teóricos e práticos atinentes às esferas acadêmica (Ensino Superior) e escolar (Educação Básica), associando o trabalho do supervisor de estágio na Universidade ao do professor regente da escola, contribui para que o aluno e futuro professor se aproprie de saberes e capacidades docentes (STUTZ, 2012). Os aspectos de ensino e aprendizagem, sob os preceitos vigotskianos da tríade didática (professor, aluno, instrumento), complexificam-se no estágio supervisionado para uma duplicação dessa tríade, na qual o aluno-professor transita e atua em ambas as esferas.

Um dos saberes em relevo contempla o saber sobre a leitura e escrita do campo literário, cuja configuração ocorre em formas semióticas recorrentes em um conjunto de gêneros textuais, considerados "configurações possíveis dos mecanismos estruturantes da textualidade, portadores de indexações sociais" imprescindíveis para as circunstâncias de produção dos textos (BRONCKART, 2006, p. 145). Sob os aportes bakhtinianos, os gêneros literários apresentam uma determinada estabilidade, que permite reconhecê-los sob diferentes dimensões, seja por parâmetros contextuais, na função social de refletir sobre a vida e bens culturais, sensibilizar ou agir sobre nossas emoções e sentimentos; seja por meio da difusão e circulação por editoras, livrarias e bibliotecas; seja ainda pelo nível organizacional ou pela configuração das unidades linguísticas (THÉVENAZ; SCHNEUWLY, 2002).

$\mathrm{O}$ estudo aprofundado das materialidades dos textos literários nas situações sócio-históricas, quando suprido por um conjunto de comentários advindos da história literária, estilística, poética ou crítica e pela compreensão do papel da escola na apreensão das heranças de 
Lidia Stutz

Claudio José de Almeida Mello obras literárias (AEBY-DAGHÉ, 2016) contempla os saberes necessários para realizar a transposição didática. Esses elementos contribuem para que o aluno na formação inicial se aproprie do gênero literário por meio de um modelo didático, "um objeto descritivo e operacional, construído para apreender o fenômeno complexo da aprendizagem de um gênero" (PIETRO et al., 1996/1997, p. 108).

No movimento da alternância entre teoria e prática própria da práxis, a mobilização das dimensões dos gêneros literários propicia ao aluno-professor a instrumentação para que ele realize mediações sólidas no ensino a ser realizado na Educação Básica. Diferentemente dos gêneros escolares, advindos das práticas tradicionais de ensino e cujos textos são construídos com um propósito didático, os gêneros literários demandam "uma transformação do gênero social em função dos princípios didáticos e legítimos em relação aos saberes de referência, da pertinência quanto às capacidades dos alunos e da solidarização em relação aos objetivos visados pelo professor" (AEBY-DAGHÉ, 2016, p. 63. Tradução nossa.).

A transposição didática de gêneros, como exposto, demanda três passos: a) a construção de um modelo didático que apresente as dimensões ensináveis; b) a construção de uma sequência didática constituída por avaliação inicial, módulos com textos, atividades para compreensão e produção do gênero, informações adicionais, textos complementares e avaliação final; c) e a prática, isto é, a sequência de ensino para realizar a mediação entre professor, alunos e o objeto de ensino.

$\mathrm{O}$ ensino da leitura-escritura literária em proposta genebrina (THÉVENAZ; SCHNEUWLY, 2002, p. 18), contempla:

a) A “sensibilização à diversidade de gêneros literários”, para que os alunos criem uma imagem dos gêneros, "um capital de recursos" variados sobre textos de gêneros diversos. Nessa fase, as bibliotecas em sala auxiliam na escolha dos livros e na apresentação realizada pelos alunos. A proposta ocorre concomitante ao trabalho com as sequências de ensino para promover a sensibilização e democratização de acesso à literatura.

b) A comparação das características próprias do mundo representado dos contos maravilhosos, de animais, de fábulas, dos relatos de aventuras e relatos fantásticos, policiais ou contos de terror, dentre outros. Thévenaz e Schneuwly (2002, p. 18) sugerem atividades como a identificação e descrição das personagens, a 
compreensão do mundo em que ocorre o seu desenvolvimento e desencadeia a relação entre o mundo real e o ficcional, para tecer relações entre os fatos plausíveis e a verossimilhança, no que tende para o maravilhoso, fantástico, de suspense, terror etc. Os elementos expostos geram a tomada de consciência sobre os mundos científicos e os mundos aculturados, que remetem a Ensino de valores, afeições, pontos de vista e representações advindas das formas de se expressar pela escrita.

c) “A utilização de dispositivos para leitura-escrita [, que] favorece a discussão do tipo interpretativa" (THÉVENAZ; SCHNEUWLY, 2002, p. 18). As sequências didáticas são constituídas por textos cujo objetivo é realizar a compreensão e a interpretação ou elucidar um problema. Juntamente com os textos, seguem as atividades constituídas de metalinguagem para auxiliar na compreensão e atingir os resultados propostos. Além dessas práticas mais sistematizadas em sala de aula, os autores sugerem a utilização de dispositivos como círculos de leitura para prover constante cotejo e confronto com os textos, incitando o aluno a diversas revisitas ao texto para desestabilizar e modificar as representações de mundo.

d) A iniciação às práticas literárias, com atividades variadas como visitas a bibliotecas, participação em sessões de leitura e encontros com escritores e editores, as quais geram maior compreensão sobre o contexto de produção das obras.

Na perspectiva apontada, o ensino da leitura-escritura literária demanda um trabalho explícito sobre o contexto de produção das obras e suas dimensões estéticas, bem como gera a necessidade de tecer relações com as experiências do leitor, que se projeta também como autor, seja como leitor-escritor de textos scriptíveis, seja como produtor de seus próprios textos literários. A proposta coaduna com o olhar de Vigotski (2006, p. 34. Tradução nossa): "Ensinar o ato criador da arte é impossível, mas isso não quer dizer que o educador não pode contribuir em sua formação, organizando de certa maneira a consciência para que vá ao encontro da arte".

A formação docente para atuar no campo literário passa, primeiramente, pela instrumentalização do professor em formação para que ele tenha respaldo para atuar e conduzir os seus alunos na tomada de consciência sobre os gêneros literários. Trata-se de uma proposta 
Lidia Stutz

Claudio José de Almeida Mello teórico-metodológica qualificada para a junção de esforços advindos das esferas acadêmica e escolar, uma parceria colaborativa tanto para a formação inicial na universidade como para a formação continuada na escola, promovendo espaços menos assimétricos e com maior integração entre os participantes das instituições envolvidas.

O êxito dessa proposta foi constatado em um estudo de Stutz, Lanferdini e Souza (2014), que analisa transposição didática do gênero literário Haikai realizado por uma acadêmica em formação inicial e uma professora regente de turma com alunos de oitavo ano do Ensino Fundamental, com o objetivo de verificar em que medida houve apreensão de saberes pelos alunos da Educação Básica e pela futura professora, discente do curso de Letras, habilitação em língua inglesa. Foram utilizados haikais de Helena Kolody, Kobayashi Issa, entre outros, considerados como uma al-

ternativa para a compreensão e produção literária em sala de aula, devido à linguagem concisa e à simplicidade temática. A partir de observações participativas, a aluna em formação fez o reconhecimento do contexto escolar, o perfil e capacidades de linguagem dos alunos e construiu o modelo didático do gênero, com o desenvolvimento da sequência didática e sua prática em sala de aula. A sequência didática seguiu a proposta de Schneuwly e Dolz (2004), com apresentação da situação, produção inicial, sete módulos e produção final. Como exemplo, apresentamos no Quadro 1 uma das atividades do primeiro módulo, com informações sobre o autor e momento de produção, o haikai em três línguas (japonês, inglês e português) e o sentimento expresso.

\section{Quadro 1: Atividade da sequência didática com Haikai}

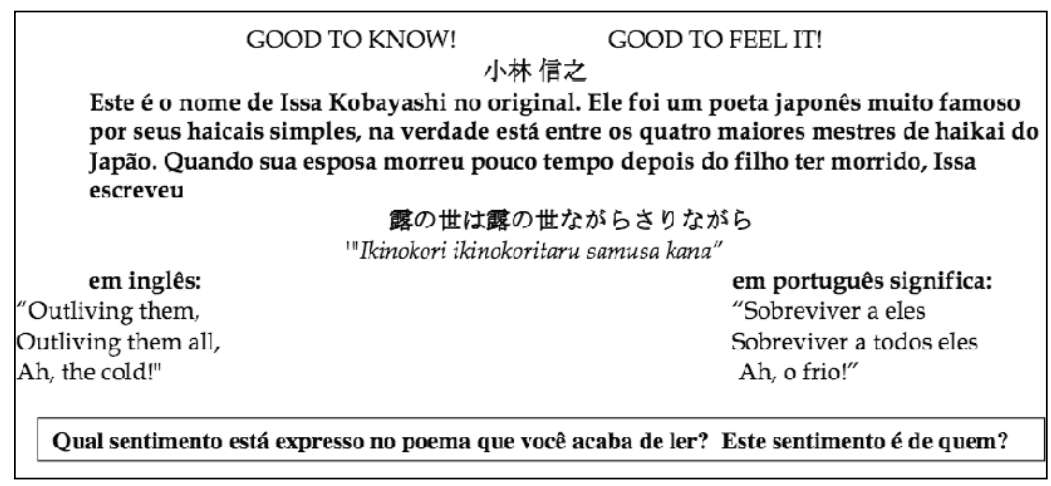

Fonte: SOUZA(2012) 
A sequência didática buscou fortalecer a subjetividade dos alunos, expressando sensações ligadas à temática dos haikais, bem como prover espaços para a produção de poemas, alçando os alunos à posição de leitores-escritores, os quais ampliaram as suas capacidades de linguagem literária e se engajaram na apreciação estética dos poemas e na produção coerente em língua inglesa. A finalização Ensino de da proposta ocorreu com a disseminação dos poemas dos alunos em literaturae forma de varal de poesias para toda a comunidade escolar. 0 instruleitura como mento sequência didática poderia induzir a uma visão tecnicista, em escritura na que apenas os elementos discursivos fossem contemplados, mas não, salientamos que há da mesma forma a necessidade de introduzir espaço para "a singularidade, a criatividade e a originalidade" (DOLZ, ABOUZAID, 2015, p. 12. Tradução dos autores) que são cruciais para formação de professores fortalecer as capacidades de linguagem e o desenvolvimento da linguagem literária na escola.

$\mathrm{Na}$ contramão de propostas meramente aplicacionistas, em que o (futuro) professor é o executor do que os materiais didáticos prescrevem, ao desenvolver a proposta de transposição didática na formação inicial de professores, percorremos um longo processo de seleção dos textos literários, estudo aprofundado da configuração do gênero haikai, construção de uma sequência didática e posterior ensino. Dessa forma, colocamos o (futuro) docente na posição de autor responsável pela proposta de compreensão e produção, ampliando duplamente os saberes, tanto com relação ao funcionamento da linguagem, neste caso do texto literário em tela, como do funcionamento da prática docente no meio escolar, provendo-lhe condições para aprimorar saberes e capacidades docentes (STUTZ, 2012). A ação de empoderamento da aluna-professora foi possível graças à sólida parceria e direcionamentos constantes da professora formadora do estágio supervisionado na universidade e da professora regente da escola. Portanto, a dupla formada pela tríade didática e pelo objeto literário Haikai ocorreu em meio à alternância da práxis na convergência de ações que fortaleceram tanto a formação inicial docente como a formação continuada da professora regente, propiciando uma aprendizagem escolar sem suprimir as diversas dimensões artísticas da literatura, como as "cognitivas, emotivas, culturais, estéticas" (DUBOIS-MARCOIN; TAUVERON, 2008). 
Lidia Stutz

Claudio José de Almeida Mello

\section{Considerações finais}

O ensino de literatura se encontra sob uma tensão constitutiva entre a transmissão de habilidades técnicas (como a análise literária, a versificação ou a compreensão da estrutura narrativa) e a capacidade de apropriação da literatura para fins existenciais (afinal, a literatura trata daquilo que somos). Mas parece certo que o que entendemos como "literatura" é diferente da "literatura ensinada" (DESCHOUX; FLOREY; RONVEAUX, 2015, p. 19). Afinal, já notou Todorov (2009) que a instituição escolar trata muito mais do ensino de conhecimentos sobre a literatura, do que da leitura literária propriamente dita, incluindo o acesso direto dos alunos-leitores aos livros.

Para os alunos em formação inicial, resulta bastante complexa a tarefa de planificar os conteúdos relacionados ao ensino de literatura. As dúvidas vão desde quais obras e gêneros selecionar até quais conhecimentos paraliterários (teóricos, históricos) são necessários para por em marcha um processo de formação do leitor, o qual deve ser, na prática, disposto por meio da transposição didática do gêneros textuais com a utilização das dimensões ensináveis do gênero em uma sequência, na autoprescrição de planos de ensino. Esses passos da transposição didática guiam o trabalho do futuro professor possibilitando a mediação para gerar compreensão e produção do texto literário com alunos da Educação Básica. A proposta visa guardar coerência entre o currículo e a progressão com que os conteúdos são trabalhados, em face das capacidades de interpretação, verbalização e produção de textos, incluindo a elaboração de textos literários próprios, não como uma atividade técnica, mas sim como uma forma de interação entre leitor, texto, subjetividade e meio social (DESCHOUX; FLOREY; RONVEAUX, 2015).

A proposta de ensino de literatura baseada no Interacionismo Sociodiscursivo, sem cisão com o ensino de língua, permite superar a divisão do trabalho presente no ensino de literatura focado na análise literária de matiz formalista (classificação do tempo, espaço, personagens, ritmo, métrica etc.) e considerar o aluno concreto, como leitor-escritor, que se apropria da literatura para a sua vida. Sobressai nesse modelo de ensino a importância da produção literária de autoria do aluno, pois, ao utilizar convenções narratológicas e poéticas dos textos lidos, o educando melhora a sua compreensão leitora, desenvolve sua própria percepção de mundo e amplia as suas capacidades de escrita. 
Assim, a literatura deixa de ser utilizada como mero objeto para exercícios de compreensão de leitura ou para estudo do funcionamento da língua, para ser considerada como artefato artístico-cultural que diz respeito ao leitor, à forma como ele se coloca em face da realidade e também como artefato que permite ao aluno a apropriação de convenções e formas de expressão. O professor, nesse caso, assume uma dupla

Ensino de literaturae leitura como escritura na formação de professores

\section{REFERÊNCIAS}

AEBY DAGHÉ, S. Candide. La fée carabine et les autres: Vers un modèle didactique d' la lecture littéraire. Berne, Suisse: Peter Lang SA, 2016.

AMORA, A. S. Introdução à teoria da literatura. São Paulo: Cultrix, 1973. 
ARISTÓTELES. Arte retórica e arte poética. Tradução de Antônio Pinto de Carvalho. Rio de Janeiro: Edições de Ouro, s.d.

BARTHES, R. O rumor da língua. São Paulo: Martins Fontes, 2004.

S/Z: uma análise da novela Sarrasine de Honeré de Balzac. Tradução de Léa Novaes. Rio de Janeiro: Nova Fronteira, 1992.

Lidia Stutz

Claudio José de Almeida Mello

BRAIT, B. Literatura e outras linguagens. São Paulo: Contexto, 2010.

BRONCKART, J.-P. Atividade de linguagem, textos e discursos. Por um interacionismo sociodiscursivo. Trad. Anna Rachel Machado, Péricles Cunha. São Paulo: EDUC, 1999.

BRONCKART, J.-P. Atividade de linguagem, discurso e desenvolvimento humano. Campinas: Mercado de Letras, 2006.

CARRELL, P. L.; DEVINE, J.; ESKEY, D. (Eds.). Interactive approaches to second language reading. NewYork: Cambridge University Press, 1988/2000.

CERUTTI-RIZZATTI, MARY ELIZABETH ; DAGA, ALINE CASSOL ; DIAS, Sabatha Catoia . Intersubjetividade e intrassubjetividade no ato de ler: a formação de leitores na Educação Básica. Calidoscopio (Online), v. 12, p. 226-238, 2014.

DESCHOUX, C; FLOREY, S.; RONVEAUX, C. Sous les pavés de la tâche, la plage des savoirs scolaires et la littérature. Formation et pratiques d'enseignement en questions, 2015, n. 19, p. 127-136.

DOLZ, J.; ABOUZAID, M. Pluralité des genres et singularité du texte: tensions constitutives de la didactique des langues. Forumleture. ch. 2015. Diponível em: <https://www.leseforum.ch/myUploadData/ files/2015_2_Dolz_Abouzaid.pdf>. Acesso em: 18 de fevereiro de 2019.

DUBOIS-MARCOIN, D.; TAUVERON, C. Présentation. Repères [On line], 37, 2008. Disponível em: <http://reperes.revues.org/417>. Acesso em: 28 de abril de 2017. 
EIKHENBAUM, B. et al. Teoria da literatura: Formalistas russos. 3. ed. Porto Alegre, Globo, 1976.

GADAMER, H. Verdade e método. Trad. Flávio Paulo Meurer. 3. ed. Petrópolis: Vozes, 1997.

Ensino de

GERALDI, J.W. Concepções de linguagem e ensino de português. In: literatura e (Org). O texto na sala de aula: leitura \& produção. 2. ed. Cascavel: ASSOESTE, 1990. p. 41-48. leitura como escritura na formação de GOODMAN, K.. Reading: a psycholinguistic guessing game. Journal professores of the Reading Specialist, v. 6, n. 4, p. 126-135, 1967.

GOUGH P. B. One second of reading. In: J. F. Kavanagh, \& I. G. Mattingly (Eds.). Language by ear and by eye. Cambridge, MA: MIT Press. 1972.

HOUDART-MÉROT, V. Da crítica de admiração à leitura "scriptível”. In: ROUXEL, A.; LANGLADE, G.; REZENDE, N. L. De (Org.). Leitura subjetiva e ensino de literatura. São Paulo: Alameda, 2013.

JAUSS, H. R. A história da literatura como desafio à teoria literária. Trad. Sérgio Tellaroli. São Paulo: Ática, 1994.

KLEIMAN, Â. Leitura, ensino e pesquisa. Campinas, SP: Pontes, 2008.

OLIVEIRA, V. da S. História literária nos cursos de Letras: cânones e tradições. Londrina, 2007. Tese (Doutorado) - Programa de Pós-graduação em Letras, Universidade Estadual de Londrina.

PERFEITO, A. M. Concepções de Linguagem, análise lingüística e proposta de intervenção. In: I Congresso Latinoamericano de Professores de Língua, Florianópolis. Anais. Florianópolis: EDUSC, 2007, p. 824-836.

PIEDRAS, M. C. Escola e história da literatura em diálogo. Porto Alegre, 2007. Dissertação (Mestrado) - Programa de Pós-graduação em Letras, Pontifícia Universidade Católica do Rio Grande do Sul. 
PIETRO, J.-F. de; ERARD, S.; KANEMAN-POUGATCH, M. Un modèle didactique du "débat": de l'objet social à la pratique scolaire. Enjeux, 1996/1997, v. 39/40, p. 100-129.

ROJO, Roxane. Letramento e capacidades de leitura para a cidadania. In: Evento da Coordenadoria de Estudos e Normas Pedagógicas (CENP-SEED/ SP), São Paulo. Anais. São Paulo, 2004.

Lidia Stutz

Claudio José de

SAUSSURE, Ferdinand. Curso de linguística geral. 15. ed. São Paulo: Almeida Mello

SANTOS, S. P. Didática do ensino da língua: concepções de linguagem e práticas docentes de leitura e escrita. Revista Arredia, p. 1-20, 2012.

SCHNEWULY, B. et al. Writing and teaching literature the role of hypertextual and metatextual writing activities at three school levels. L1 Educational Studies in Languages and Literature, v. 16-17, 2017.

SCHNEUWLY, B.; DOLZ, J. Gêneros orais e escritos na escola. Trad. Roxane Rojo; Glaís Sales Cordeiro. Campinas: Mercado de Letras, 2004.

STUTZ, L.; LANFERDINI, P.A.F.; SOUZA, J. S. Trabalho de parceria entre a universidade e a escola: uma experiência de intervenção de ensino mediada pela proposta de elaboração de sequências didáticas. In: BARROS, E. D. M.; RIOS-REGISTRO, E. S. (Org.). Experiências com sequências didáticas de gêneros textuais. Campinas: Pontes, 2014, v. 1, p. 100-125.

STUTZ, L. Sequências didáticas, socialização de diários e autoconfrontação: instrumentos para a formação inicial de professores de inglês. 2012, $458 \mathrm{f}$. Tese (Doutorado em Estudos da Linguagem) - Universidade Estadual de Londrina, 2012.

SOUZA, J. S. Sequência didática HAIKAI. Guarapuava, 2012. (Mimeo).

SOARES, M. B. Concepções de linguagem e o ensino de língua portuguesa. In: BASTOS, N. B. (org.). Língua portuguesa: história, perspectivas, ensino. São Paulo: EDUC, 1998. p. 53-60. 
THÉVENAZ, T.; SCHNEUWLY, B. Enseignemant de la lecture-écriture littéraire. Résonances, 2002, n. 9, p. 17-19.

TODOROV, T. A literatura em perigo. Trad. Caio Meira. 2. ed. Rio de Janeiro: DIFEL, 2009.

VIGOTSKI, L. S. Pensamento e linguagem. 4. ed. São Paulo: Martins Fontes, 1987/2008.

Ensino de

literaturae

leitura como

escritura na

VIGOTSKI, L. Psicologia del arte. Madrid: Paidos Iberica, 2006.

formação de

professores

VILLALTA, L. C. O que se faz e o que se lê: língua, instrução e leitura. In: SOUZA, L. de M. (org.). História da vida privada no Brasil. São Paulo: Companhia das Letras, 1997.

VOLOCHINOV, V. N. Marxismo e filosofia da linguagem: problemas fundamentais do método sociológico na ciência da linguagem. 14 . ed. Sao Paulo: Hucitec, 2010.

WITZEL, D; MELLO, C. Do signo às relações discursivas: contribuições da Análise do Discurso para a educação literária a partir da escola. Raído, Dourados, v. 9, n. 19, 2015. 
